\title{
Specialty-based, voluntary incident reporting in neonatal intensive care: description of 4846 incident reports
}

\author{
C Snijders, ${ }^{1,2}$ R A van Lingen, ${ }^{1}$ H Klip, ${ }^{3}$ W P F Fetter ${ }^{4}$ T W van der Schaaf, ${ }^{5,6}$ \\ $\mathrm{H}$ A Molendijk, ${ }^{1}$ on behalf of the NEOSAFE study group
}

- The NEOSAFE report form (online appendix A) is published online only at http://adc.bmj. com/content/vol94/issue3

${ }^{1}$ Princess Amalia Department of Paediatrics, Division of Neonatology, Isala Clinics, Zwolle, The Netherlands; 2 Juliana Children's Hospital, Haga Hospital, The Hague, The Netherlands; ${ }^{3}$ Research Bureau, Isala Clinics, Zwolle, The Netherlands; ${ }^{4}$ Department of Paediatrics, Division of Neonatology, VU University Medical Center, Amsterdam, The Netherlands; ${ }^{5}$ Division of Patient Safety, Hasselt University, Diepenbeek, Belgium;

${ }^{6}$ Faculty of Technology Management, Eindhoven University of Technology, Eindhoven, The Netherlands

Correspondence to: C Snijders, Haga Hospital, Location Juliana Children's Hospital, Sportlaan 600, 2566 MJ The Hague, The Netherlands; c.sniijders@ grimbergen.net

Accepted 4 September 2008 Published Online First 6 October 2008

\section{ABSTRACT}

Objectives: To examine the characteristics of incidents reported after introduction of a voluntary, non-punitive incident reporting system for neonatal intensive care units (NICUs) in the Netherlands; and to investigate which types of reported incident pose the highest risk to patients in the NICU.

Design: Prospective multicentre survey.

Methods: Voluntary, non-punitive incident reporting was introduced in eight level III NICUs and one paediatric surgical ICU. An incident was defined as any unintended event which (could have) reduced the safety margin for the patient. Multidisciplinary, unit-based patient safety committees systematically collected and analysed incident reports, and assigned risk scores to each reported incident. Data were centrally collected for specialty-based analysis. This paper describes the characteristics of incidents reported during the first year. Bivariate logistic regression analysis was conducted to identify high-risk incident categories.

Results: There were 5225 incident reports on 3859 admissions, of which 4846 were eligible for analysis. Incidents with medication were most frequently reported $(27 \%)$, followed by laboratory $(10 \%)$ and enteral nutrition (8\%). Severe harm was described in seven incident reports, and moderate harm in 63 incident reports. Incidents involving mechanical ventilation and blood products were most likely to be assigned high-risk scores, followed by those involving parenteral nutrition, intravascular lines and medication dosing errors.

Conclusions: Incidents occur much more frequently in Dutch NICUs than has been previously observed, and their impact on patient morbidity is considerable. Reported incidents concerning mechanical ventilation, blood products, intravascular lines, parenteral nutrition and medication dosing errors pose the highest risk to patients in the NICU.

The care of newborn infants in neonatal intensive care units (NICUs) is associated with great risks to these extremely vulnerable patients. ${ }^{1-3}$ In the growing attention being paid to patient safety, reporting systems have been mentioned as a key strategy for learning from incidents and for monitoring progress in the prevention of their reoccurrence. ${ }^{45}$ Several researchers have reported that voluntary, non-punitive reporting of incidents -including both adverse events and near misses-generates large volumes of valuable information on type, aetiology, outcome and preventability of incidents. ${ }^{15-7}$ The benefits of specialtybased reporting programmes have also been described. ${ }^{5-9}$ Suresh and colleagues found that multi-institutional reporting in NICUs identified

\section{What is already known on this topic}

- The NICU poses great risks to extremely vulnerable patients.

- Reporting systems are mentioned as one of the key strategies for learning from incidents and for monitoring progress in the prevention of their reoccurrence.

- Multi-institutional, voluntary, non-punitive reporting of incidents is likely to generate valuable information on incidents in the NICU.

\section{What this study adds}

- The first specialty-based study of locally reported incidents in the NICU, covering over $80 \%$ of the national NICU population.

- Incidents in the NICU occur much more frequently than previously observed, and their impact on patient morbidity is considerable.

- Reported incidents involving mechanical ventilation, blood products, intravascular lines, parenteral nutrition and medication dosing errors pose the highest risk to patients in the NICU, and should be prioritised for indepth analysis.

rare but important errors, as well as error patterns that were unique to the specialty-such as infants being fed breast milk from the wrong mother. ${ }^{9}$ In NICUs in the Netherlands, the traditional approach is mandatory reporting to a central hospital committee (MIP) of only those incidents associated with significant patient harm and catastrophic incidents. Therefore, the impact of incidents in NICUs in the Netherlands is probably underestimated. This is supported by the results of a pilot study in a Dutch NICU, where the introduction of voluntary, non-punitive incident reporting to a local NICU committee resulted in a fivefold increase in the number of incident reports. ${ }^{10}$ This pilot study proposed a nationwide approach to incidents in the NICU through the introduction of a voluntary, non-punitive incident reporting system for Dutch NICUs. Based on the available NICU data from 2002 to 2004, the average number of incidents reported to a MIP was 13 per 100 NICU admissions. With the expected increase in reported incidents after the 
Table 1 Risk scores for reported incidents*

\begin{tabular}{|c|c|c|c|c|c|}
\hline \multirow[b]{2}{*}{$\begin{array}{l}\text { Likelihood of } \\
\text { reoccurrence }\end{array}$} & \multicolumn{5}{|c|}{ Potential consequences } \\
\hline & Death & Severe & Moderate & Minor & Insignificant \\
\hline $\begin{array}{l}\text { Within several hours to } \\
\text { days }\end{array}$ & 4 & 4 & 3 & 2 & 2 \\
\hline Within several weeks & 4 & 4 & 3 & 2 & 2 \\
\hline Within several months & 4 & 3 & 3 & 2 & 1 \\
\hline Once in $1-5$ years & 4 & 3 & 2 & 1 & 1 \\
\hline $\begin{array}{l}\text { Less than once in } 5 \\
\text { years }\end{array}$ & 3 & 2 & 2 & 1 & 1 \\
\hline
\end{tabular}

*Consensus was provided by an interdisciplinary NEOSAFE meeting; $4=$ extreme risk, $3=$ major risk, $2=$ moderate risk, $1=$ minor risk.

introduction of a voluntary reporting system, selection and prioritisation for indepth analysis become critical steps in handling the large number of incident reports. ${ }^{11}$ The objectives of this study were:

- to describe the characteristics of incidents reported in Dutch NICUs during the first year after introduction of a specialtybased, voluntary, non-punitive incident reporting system;

- to investigate which types of reported incident pose the greatest risk to patients in the NICU.

\section{METHODS}

\section{Setting}

From December 2004 to June 2005, a Neonatology System for Analysis and Feedback on medical Events (NEOSAFE) was implemented in eight of the 10 Dutch NICUs (14-24 beds per NICU) and one paediatric surgical ICU (14 beds, 15\% neonates). All units, with a total of approximately 3500 admissions each year, provide tertiary care. Extracorporal membrane oxygenation (ECMO) is provided in only two units.

\section{Data collection and handling}

Voluntary, non-punitive incident reporting was introduced to establish specialty-based learning from incidents. Patient safety was defined $a s^{12}$ :

the avoidance and prevention of patient injuries or adverse events resulting from the process of health care delivery.

An incident was defined $a s^{6}$ :

any event which could have reduced, or did reduce the safety margin for the patient.

In each unit a multidisciplinary patient safety committee (PSC) was formed, and one nurse and one doctor were appointed as the local coordinators. A system approach (PRISMA-medical method) was used to analyse the causes of incidents, investigating system deficiencies rather than personal failure. ${ }^{813-15}$ Results of this analysis will be presented in consecutive work. Unit employees were encouraged to communicate openly following incidents, and to report incidents non-anonymously to enable contact with the reporter if any additional information was needed during analysis. Personnel were asked to fill in an incident report form immediately after discovery of an incident. Incidents were either self-reported or reported by personnel who discovered the incident. We developed a standardised report form on the basis of recommendations from the Institute of Medicine. ${ }^{4}$ This form included a narrative section, predefined items, and a section including potential severity, risk for reoccurrence, risk scores (table 1), and
Inclusion criteria:

Incident reported to the NEOSAFE

database between 1 July 2005 and

30 June 2006

Valid, unique incident report code

Incident is not a duplicate (only first

observation used from reports that

matched on unit number, date,

incident type and free text description)

Exclusion criteria:

1. Free text description $=$ missing $(n=9)$ OR

2. Potential severity score $=$ missing $(n=161)$ OR

3. Actual severity score $=$ missing $(n=181)$ OR

4. Combination of $1 / 2 / 3 /(n=28)$

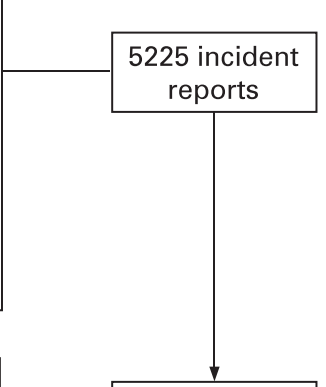

-379 incident reports

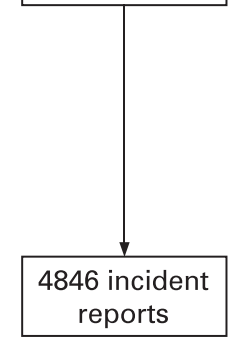

Figure 1 Selection of incident reports.

planned actions (free text, optional) to be filled in by the PSC during analysis (see online appendix A: NEOSAFE report form). An interdisciplinary meeting provided consensus on incident categorisation and on classification of (potential) severity and risk for reoccurrence.

The PSCs managed an electronic database (Microsoft Access) of reported incidents and results of the subsequent analysis. Incident report forms were labelled with a unique confidential code, and patient and staff confidentiality were ensured by excluding personal identification from the electronic database. Each month, the PSCs provided unit personnel with a summary of reported incidents as well as planned preventive actions related to incidents in their unit. From July 2005, local electronic databases were forwarded to the central investigator (CS) every month and aggregated for specialty-based analysis. To stimulate specialty-based learning, results of local incident reporting, analysis, and planned actions for prevention were discussed at sixmonthly NEOSAFE meetings with the PSCs. The local medical research ethics committee (METC Zwolle) was consulted, which confirmed that this study did not require approval for implementation as it only involved the registration of incidents.

\section{Data analysis}

The local databases were aggregated for specialty-based analysis. Figure 1 shows how incident reports were selected for analysis. In this paper we describe the characteristics of incidents reported between 1 July 2005 and 30 June 2006, with respect to incident type, incident description, (potential) severity, staff and patient factors, time and place, and method of detection. For each incident category, bivariate logistic regression analysis was conducted to estimate the odds ratio for inducing high-risk incidents (table 1, risk scores 3 and 4). Each odds ratio referred to the proportion of an individual type of incident in relation to all other types. The variables unit, birth weight, gestational age, and actual age were selected for possible correction and considered a confounder in the event inclusion into the model resulted in a $\geqslant 10 \%$ change in the coefficient of the incident category being modelled. ${ }^{16}$ SPSS V.12.0.1 was used for analyses. Results are 
Table 2 Unit characteristics and reporting rate

\begin{tabular}{|c|c|c|c|c|c|c|c|c|c|c|}
\hline & \multicolumn{9}{|l|}{ Unit } & \multirow[b]{2}{*}{ Total } \\
\hline & A & B & C & $D^{*}$ & $\mathbf{E}$ & $\mathbf{F}$ & G & H & $I$ & \\
\hline No of beds & 18 & 23 & 24 & 5 & 20 & 24 & 14 & 17 & 17 & 162 \\
\hline \multicolumn{11}{|c|}{ No of incident reports } \\
\hline July-Dec 2005 & 201 & 249 & 669 & 315 & 172 & 177 & 271 & 331 & 161 & 2546 \\
\hline Jan-June 2006 & 154 & 255 & 676 & 281 & 164 & 172 & 210 & 234 & 154 & 2300 \\
\hline Total & 355 & 504 & 1345 & 596 & 336 & 349 & 481 & 565 & 315 & 4846 \\
\hline \multicolumn{11}{|c|}{ No of incident reports/admission } \\
\hline July-Dec 2005 & 0.72 & 0.88 & 2.34 & $4 \quad 4.09$ & 0.83 & 0.60 & 1.99 & 1.56 & 1.06 & 1.32 \\
\hline Jan-June 2006 & 0.57 & 0.94 & 2.05 & $5 \quad 4.53$ & 0.70 & 0.63 & 1.71 & 1.04 & 1.05 & 1.19 \\
\hline Total & 0.65 & 0.91 & 2.19 & $\begin{array}{l}9 \\
9\end{array}$ & 0.76 & 0.62 & 1.86 & 1.29 & 1.06 & 1.26 \\
\hline
\end{tabular}

*Only data on neonates were selected from the paediatric surgical intensive care unit.

presented as odds ratios with $95 \%$ confidence intervals. We used a significance level of $\mathrm{p}<0.05$.

\section{RESULTS}

During the study period, 4846 incident reports (on 3859 admissions) were included for analysis. The number of reports from each unit varied slightly during the study period (table 2).

Most incidents (92\%) took place during regular care, and the majority $(73 \%)$ were discovered by nursing staff. Median birth weight of patients involved in reported incidents was $1463 \mathrm{~g}$ (range 440-5630 g). Median gestational age was 31 weeks (range $24-43^{+6}$ weeks). Median actual age was $33^{+4}$ weeks, corrected for preterm birth (range $24^{+1}$ to 59 weeks). Eighty-eight per cent of incidents were reported by nursing staff, and $11 \%$ by doctors.

Incident categorisation into six major categories and several subcategories is shown in Table 3 . Incidents associated with medication were the most commonly reported, followed by laboratory and enteral nutrition incidents. Descriptions of

Table 3 Incident categorisation

\begin{tabular}{|c|c|c|c|}
\hline Main type & No $(\%)$ & Subtype & No $(\%)^{*}$ \\
\hline \multirow[t]{7}{*}{ 1. Mechanical ventilation } & $414(9)$ & Machine & $122(2.5)$ \\
\hline & & Tube & $109(2.2)$ \\
\hline & & Humidification & $72(1.5)$ \\
\hline & & Connecting tubes & $17(0.4)$ \\
\hline & & Trachea cannula & $3(0.1)$ \\
\hline & & Other subtype & $83(1.7)$ \\
\hline & & Combination of subtypes & $8(0.2)$ \\
\hline \multirow[t]{4}{*}{ 2. Intravascular lines/cannulas } & $459(9)$ & Peripheral infusion cannula & $214(4.4)$ \\
\hline & & Venous line & $158(3.3)$ \\
\hline & & Arterial line & $76(1.6)$ \\
\hline & & Both venous and arterial line & $11(0.2)$ \\
\hline \multirow[t]{11}{*}{ 3. Other material/equipment } & $669(14)$ & Monitor & $72(1.5)$ \\
\hline & & Feeding catheter & $56(1.2)$ \\
\hline & & Low flow & $44(0.9)$ \\
\hline & & CPAP & $42(0.9)$ \\
\hline & & Urinary catheter & $29(0.6)$ \\
\hline & & Suction catheter & $24(0.5)$ \\
\hline & & ECMO & $22(0.5)$ \\
\hline & & Drain & $20(0.4)$ \\
\hline & & Pump & $14(0.3)$ \\
\hline & & Other subtype & $341(7.0)$ \\
\hline & & Combination of subtypes & $5(0.1)$ \\
\hline \multirow[t]{4}{*}{ 4. Medication/nutrition/blood products } & $2045(42)$ & Medication & $1321(27.3)$ \\
\hline & & Enteral nutrition & $368(7.6)$ \\
\hline & & Parenteral nutrition & $304(6.3)$ \\
\hline & & Blood products & $52(1.1)$ \\
\hline \multirow[t]{5}{*}{ 5. Diagnostic procedures } & $621(13)$ & Laboratory & $501(10.3)$ \\
\hline & & $X$ ray & $41(0.8)$ \\
\hline & & Ultrasound & $3(0.1)$ \\
\hline & & Other subtype & $72(1.5)$ \\
\hline & & Combination of subtypes & $4(0.1)$ \\
\hline 6. Other incident & $557(11)$ & & \\
\hline Subtotal & 4765 & & \\
\hline Combination of incident types & $81(2)$ & & \\
\hline Total & 4846 & & \\
\hline
\end{tabular}

*Within the total group of incidents.

CPAP, continuous positive airway pressure; ECMO, extracorporal membrane oxygenation. 
Table 4 Incident description

\begin{tabular}{|c|c|c|}
\hline Incident type & Description* & No (valid \%) \\
\hline \multirow{13}{*}{$\begin{array}{l}\text { Mechanical ventilation/intravascular lines/cannulas/other material/ } \\
\text { equipment }(n=1542) \dagger\end{array}$} & Wrong settings & $260(6.2)$ \\
\hline & Unplanned removal & $147(3.5)$ \\
\hline & Wrong usage & $92(2.2)$ \\
\hline & Loosening & $79(1.9)$ \\
\hline & Subcutaneous infusion & $74(1.8)$ \\
\hline & Dysfunctional machine & $75(1.8)$ \\
\hline & Wrong connection & $64(1.5)$ \\
\hline & Material damage & $43(1.0)$ \\
\hline & Unavailable & $33(0.8)$ \\
\hline & Occlusion & $29(0.7)$ \\
\hline & Prolonged indwelling time & $17(0.4)$ \\
\hline & Other & $471(11.2)$ \\
\hline & Combination of descriptions & $65(1.5)$ \\
\hline \multirow[t]{11}{*}{ Medication/nutrition/blood products $(\mathrm{n}=2045)$} & Wrong dose & $463(11.0)$ \\
\hline & Wrong infusion rate & $214(5.1)$ \\
\hline & Wrong time & $143(3.4)$ \\
\hline & Incomplete administration & $126(3.0)$ \\
\hline & Wrong concentration & $105(2.5)$ \\
\hline & Wrong product & $102(2.4)$ \\
\hline & Wrong route of administration & $52(1.2)$ \\
\hline & Product out of date & $50(1.2)$ \\
\hline & Patient misidentification & $47(1.1)$ \\
\hline & Other & $563(13.4)$ \\
\hline & Combination of descriptions & $102(2.4)$ \\
\hline \multirow{10}{*}{ Diagnostic procedures $(n=621)$} & Exam not performed & $140(3.3)$ \\
\hline & Unnecessary exam & $61(1.5)$ \\
\hline & Delayed results & $46(1.1)$ \\
\hline & Material not received & $26(0.6)$ \\
\hline & Wrong time & $21(0.5)$ \\
\hline & Wrong test requested & $15(0.4)$ \\
\hline & Patient misidentification & $12(0.3)$ \\
\hline & Wrong test performed & $8(0.2)$ \\
\hline & Other & $219(5.2)$ \\
\hline & Combination of descriptions & $38(0.9)$ \\
\hline Other incident/combination of incidents ( $n=638$ ) & Other & $196(4.7)$ \\
\hline Total & & $4198 \%$ \\
\hline
\end{tabular}

*The predefined incident descriptions were divided into three main groups, relating to different stages in the process of care. $\dagger$ These three main types of incidents were related to the same set of incident descriptions.

Descriptions were missing in 648/4846 incident reports.

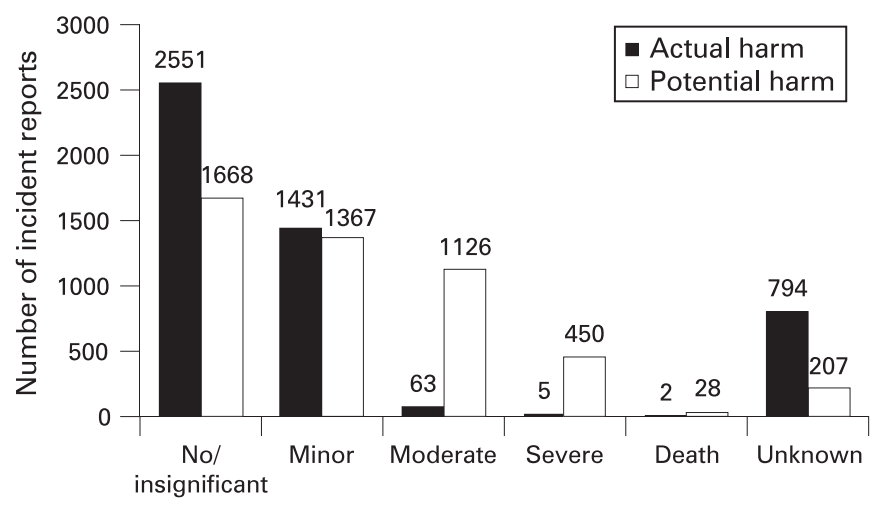

Figure 2 Incident severity $(\mathrm{n}=4846)$. Minor, temporary minor harm not involving prolonged stay in the hospital; moderate: permanent minor harm not involving prolonged stay in the hospital or temporary major harm involving prolonged stay in hospital; severe, permanent major harm involving prolonged stay in hospital. incidents are given in Table 4. Many incidents involved wrong dose, wrong ventilator settings or wrong infusion rate. The administration of the wrong product was less frequently reported but it was still considered an important error (102 reports $(2.4 \%)$, including medication $(n=48)$, nutrition (enteral $\mathrm{n}=22$, parenteral $\mathrm{n}=29)$, and blood products $(\mathrm{n}=3)$ ).

\section{Incident severity}

Figure 2 shows actual and potential severity. Significant patient harm (moderate or severe harm) was described in 70 incident reports. Two of these incidents may have contributed to the death of a patient (a 10-fold morphine overdose in a premature, unstable patient; and dysfunctional cerebral function monitoring that delayed treatment of seizures). Another five incidents were expected to result in permanent major harm: 3-day delay in test results for congenital hypothyroid disorder, defective ventilator resulting in severe metabolic acidosis, arterial line occlusion resulting in foot necrosis, burns due to chlorhexidene, and skin necrosis after subcutaneous infusion of packed cells. The remaining 63 incidents involved mechanical ventilation $(n=14)$, intravascular lines $(n=7)$, medication $(n=7)$, peripheral infusion cannulas $(n=8)$, other material/equipment 
Table 5 Identification of high-risk incident types

\begin{tabular}{|c|c|c|}
\hline \multirow[b]{2}{*}{ Incident type $(n=4846)$} & \multirow{2}{*}{$\begin{array}{l}\begin{array}{l}\text { High risk score } \\
\text { (score } 3 \text { or } 4 \text { ) }\end{array} \\
\text { No (valid \%) } \dagger\end{array}$} & \multirow[b]{2}{*}{ Odds ratio* $(95 \% \mathrm{Cl})$} \\
\hline & & \\
\hline Mechanical ventilation $(n=414)$ & $211(52)$ & $2.45(2.00$ to 3.02$)$ \\
\hline \multicolumn{3}{|l|}{ Intravascular lines/cannulas } \\
\hline Intravascular lines $(n=245)$ & $93(39)$ & $1.32(1.01$ to 1.72$)$ \\
\hline Peripheral infusion cannulas $(n=214$ ) & $61(30)$ & $0.92 \%(0.67$ to 1.25$)$ \\
\hline Other material/equipment $(n=669)$ & $204(32)$ & $0.95 \$(0.79$ to 1.13$)$ \\
\hline \multicolumn{3}{|l|}{ Medication/nutrition/blood products } \\
\hline Blood products $(n=52)$ & $28(56)$ & $2.64(1.50$ to 4.62$)$ \\
\hline Parenteral nutrition $(n=304)$ & $118(41)$ & $1.36(1.06$ to 1.73$)$ \\
\hline Medication $(n=1321)$ & $387(31)$ & $0.86(0.74$ to 0.99$)$ \\
\hline Wrong dose/infusion rate (376) & $152(43)$ & 1.59 (1.28 to 1.99$)$ \\
\hline Enteral nutrition $(\mathrm{n}=368)$ & $48(14)$ & $0.31(0.23$ to 0.43$)$ \\
\hline Diagnostic procedures $(n=621)$ & $141(24)$ & $0.62(0.51$ to 0.76$)$ \\
\hline Other incident type ( $n=557)$ & $194(37)$ & $1.23(1.02$ to 1.49$)$ \\
\hline Combination of incident types $(n=81)$ & $27(35)$ & $1.13 \%(0.70$ to 1.82$)$ \\
\hline
\end{tabular}

$(\mathrm{n}=8)$, parenteral nutrition $(\mathrm{n}=3)$, diagnostic procedures $(n=2)$, and other $(n=14)$. Potential moderate or severe harm was identified in 1604 incident reports (0.42 incident report/ admission), and 28 of these incidents (0.007/admission) were expected to be potentially lethal. Almost a third of incident reports with no or minor actual harm were expected to cause potential moderate harm, severe harm or death.

\section{Risk scores}

Two per cent of the incident reports were assigned to the highest risk score (score 4), 31\% to risk score 3, 39\% to risk score 2 , and $28 \%$ to the lowest risk score (table 1). As shown in table 5 , relative to all other incident categories, incidents related to blood products and mechanical ventilation were most likely to classify into the highest risk scores $(n=28 / 52$, OR 2.64 (95\% CI 1.50 to 4.62 ), and $n=211 / 414$, OR 2.45 (95\% CI 2.00 to 3.02 ), respectively), followed by parenteral nutrition (OR 1.36) and intravascular lines (OR 1.32). Incidents related to enteral nutrition were least likely to classify into the highest risk scores (OR 0.31), followed by diagnostic procedures (OR 0.62), and medication (OR 0.86). However, a subgroup of medication incidents pertaining to an incorrect dose or infusion rate was more likely to classify into the high risk scores (OR 1.59).

\section{DISCUSSION}

This is the first specialty-based study of locally reported incidents in the NICU, covering over $80 \%$ of the national NICU population. Incidents occur much more frequently in our NICUs than has been previously observed, and their impact on patient morbidity is considerable. Voluntary incident reporting generated large volumes of incident reports in all participating units. Although the majority of incidents had no actual severe consequences at the time of reporting, many reported incidents were thought to be potentially harmful. Based on the expected frequency of reoccurrence and the potential for harm, the overall risk for patients was high. Thus, the introduction of voluntary, non-punitive incident reporting stimulated personnel to report a great number of high-risk incidents that were captured before they resulted in actual patient harm. The enormous amount of information collected through these near miss incident reports can be very useful in the development of preventive strategies. ${ }^{17} 18$

Two similar studies exist on voluntary, non-punitive incident reporting in the NICU. ${ }^{39}$ However, Suresh and colleagues' multicentre study used external, internet-based reporting by a selected group of healthcare providers, and the other study was performed in a combined NICU/PICU. ${ }^{39}$ The number of incidents reported to NEOSAFE exceeds the number of reports in both these studies, although the absolute number of incidents resulting in severe or moderate harm was comparable with the multicentre NICU study by Suresh and colleagues. ${ }^{9}$ The possibility of personal feedback from the local PSC after nonanonymous local reporting, combined with repeatedly encouraging all personnel to report incidents, may have generated a better reporting climate in our NICUs compared with the other two studies. This is supported by the finding that unit $\mathrm{D}$, which introduced a check for incidents to be reported after every shift, generated the most incident reports (table 2).

We found that incidents relating to medication were most frequently reported. This is a common finding in the patient safety literature. ${ }^{6}{ }^{19}$ The relative number of medication incidents $(27 \%)$ is comparable with those reported by Frey and colleagues ( $29 \%$ of all incident reports). ${ }^{3}$ Suresh and colleagues ${ }^{9}$ reported a $47 \%$ incidence of reports on medication, nutrition, or blood products, compared with $42 \%$ reported to NEOSAFE. Several other studies exist on medication incidents that are actually or potentially harmful to patients in the NICU. ${ }^{20-22}$ Similar to our findings, dosing errors are frequently reported. ${ }^{21-23}$ Most important, a substantial number of medication incidents are found to be preventable. ${ }^{21} 24$

The greatest risk for the patient was found among incident reports pertaining to mechanical ventilation and blood products, followed by intravascular lines and parenteral nutrition. The importance of these incident categories is supported by several studies outside the NICU. ${ }^{14}{ }^{25-27}$ Interestingly, compared with all other reported incidents, the total group of medication incidents was less likely to classify into the highest risk scores, while a subgroup of the two most frequently reported medication incidents-wrong dose and wrong infusion ratewas more likely to classify into the highest-risk scores. This finding is consistent with a recent study concerning proactive risk assessment of the medication use process in the NICU, 
where the highest risk procedures were found to occur in the administration stage, with common potential failures relating to error in dose and infusion pump settings. ${ }^{28}$ In our study, many incidents that resulted in actual severe or moderate harm related to one of the high-risk categories. Therefore, we propose that in voluntary incident reporting systems in the NICU, these high-risk incident categories are selected for analysis of fundamental causes, and prioritised in the development of preventive strategies. ${ }^{29}$ Moreover, since some incident categories-blood products for instance-were relatively rare, collection of specialty-based incident reports on a nationwide level can reveal much more information regarding these incidents than local collection alone. ${ }^{9}$

Our study had some limitations. First, in a database of voluntary reported incidents, some incident types may be better represented than others. Therefore, the actual number of incidents will be higher. Other methods should be used to detect incident types that are likely to be under-reported in voluntary systems, for instance nosocomial infections. ${ }^{30}{ }^{31}$ However, the results of our study show that voluntary reporting can generate large volumes of information on incidents with (potentially) severe patient harm. Moreover, a specialty-based database of voluntary reported incidents gives a good interpretation of the nature of incidents that are judged important enough to report. This may lead to better compliance to the implementation of future preventive strategies that are based on these incident reports.

Second, we did not describe any preventive actions. Although several corrective actions have been taken in the participating NICUs on the basis of reported incidents, these were often ad hoc and based on local information. Moreover, the beneficial effects of system changes on patient safety in neonatal intensive care were difficult to assess from the available evidence. ${ }^{7}$ Therefore, our future studies will focus on further specification of the causes of high-risk incidents in this specialty using PRISMA analysis, ${ }^{15}$ and on the development of more powerful methods for prevention.

\section{CONCLUSIONS}

Incidents occur much more frequently in Dutch NICUs than has been previously observed, and their impact on patient morbidity is considerable. Reported incidents involving mechanical ventilation, blood products, intravascular lines parenteral nutrition and medication dosing errors pose the highest risk to patients in the NICU and should be prioritised for indepth analysis and specialty-based learning.

Acknowledgements: We would like to thank the unit PSCs for their contribution to collection and analysis of incident reports.

Funding: This study was supported by a grant from the Dutch Association of Medical Specialists.

Competing interests: None.

Ethics approval: The local medical research ethics committee (METC Zwolle) was consulted and confirmed that this study did not require approval for implementation as it only involved the registration of incidents.

\section{The NEOSAFE study group}

Neonatal Intensive Care Units:

Academic Medical Center, Amsterdam: J H Kok, E te Pas; Erasmus MC-University Medical Center, Rotterdam: H Pas, C van der Starre; Haga Hospital, The Hague: E Bloemendaal, R H Lopes Cardozo, A M Molenaar; Isala Clinics, Zwolle: A Giezen, R A van Lingen, H E Maat, A Molendijk, C Snijders; Maastricht University Medical Center: S Lavrijssen, A L M Mulder; Máxima Medical Center, Veldhoven: M J K de Kleine, A M P Koolen, M Schellekens: Radboud University Medical Centre Nijmegen: W Verlaan, S Vrancken; VU University Medical Center, Amsterdam: W P F Fetter, L Schotman, A van der Zwaan

Paediatric Surgical Intensive Care Unit:

Erasmus MC-University Medical Center, Rotterdam: C van der Starre, Y van der Tuijn, D Tibboel

\section{Other departments:}

Division of Patient Safety, Hasselt University, Diepenbeek, Belgium, and Faculty of Technology Management, Eindhoven University of Technology: T W van der Schaaf; Research Bureau, Isala Clinics, Zwolle: H Klip, B J Kollen

\section{REFERENCES}

1. Wu AW, Pronovost P, Morlock L. ICU incident reporting systems. J Crit Care 2002;17:86-94.

2. Weingart SN, Wilson RM, Gibberd RW, et al. Epidemiology of medical error. BMJ 2000;320:774-7.

3. Frey $\mathbf{B}$, Kehrer $\mathbf{B}$, Losa $\mathbf{M}$, et al. Comprehensive critical incident monitoring in a neonatal-pediatric intensive care unit: experience with the system approach. Intensive Care Med 2000;26:69-74.

4. Aspden PH, Corrigan JM, Wolcott J. Patient safety: achieving a new standard for care. Washington DC: National Academies Press, 2004.

5. Leape LL. Reporting of adverse events. N Engl J Med 2002;347:1633-8.

6. Beckmann U, Baldwin I, Hart GK, et al. The Australian Incident Monitoring Study in Intensive Care: AIMS-ICU. An analysis of the first year of reporting. Anaesth Intensive Care 1996;24:320-9.

7. Snijders C, van Lingen RA, Molendijk A, et al. Incidents and errors in neonatal intensive care: a review of the literature. Arch Dis Child Fetal Neonatal Ed 2007;92:F391-8.

8. Battles JB, Kaplan HS, Van der Schaaf TW, et al. The attributes of medical eventreporting systems. Experience with a prototype medical event-reporting system for transfusion medicine. Arch Pathol Lab Med 1998;122:231-8.

9. Suresh G, Horbar JD, Plsek P, et al. Voluntary anonymous reporting of medical errors for neonatal intensive care. Pediatrics 2004;113:1609-18.

10. Molendijk A, Borst K, van den Dolder R. [To err is human. Blamefree reporting increases transparency.] Medisch Contact 2003;43:1658-61. (In Dutch.)

11. Kaplan HS, Rabin Fastman B. Organization of event reporting data for sense making and system improvement. Qual Saf Health Care 2003;12(suppl 2):iï8-72.

12. Sorra JS, Nieva VF. Hospital survey on patient safety culture. (Prepared by Westat, under Contract No 290-9609994). AHRO Publication No 04-0041. Rockville MD: Agency for Healthcare Research and Quality, 2004.

13. Reason J. Human error: models and management. BMJ 2000;320:768-70.

14. Kaplan HS, Battles JB, Van der Schaaf TW, et al. Identification and classification of the causes of events in transfusion medicine. Transfusion 1998;38:1071-81.

15. Van der Schaaf TW, Habraken MMP. PRISMA-Medical: a brief description. Eindhoven: Eindhoven University of Technology, 2005. http://www.who.int/ patientsafety/taxonomy/PRISMA_Medical.pdf (accessed 11Aug 2008).

16. Twisk JWR. Applied multilevel analysis: a practical guide. Cambridge: Cambridge University Press, 2006

17. Wright L, Van der Schaaf TW. Accident versus near miss causation: a critical review of the literature, an empirical test in the UK railway domain, and their implications for other sectors. J Hazard Mater 2004;111:105-10.

18. Barach $\mathbf{P}$, Small SD. Reporting and preventing medical mishaps: lessons from nonmedical near miss reporting systems. BMJ 2000;320:759-63.

19. Nakajima K, Kurata $Y$, Takeda H. A web-based incident reporting system and multidisciplinary collaborative projects for patient safety in a Japanese hospital. Qual Saf Health Care 2005;14:123-9.

20. Frey B, Buettiker V, Hug Ml, et al. Does critical incident reporting contribute to medication error prevention? Eur J Pediatr 2002;161:594-9.

21. Kaushal R, Bates DW, Landrigan C, et al. Medication errors and adverse drug events in pediatric inpatients. JAMA 2001;285:2114-20.

22. Simpson JH, Lynch R, Grant J, et al. Reducing medication errors in the neonatal intensive care unit. Arch Dis Child Fetal Neonatal Ed 2004;89:F480-2.

23. Chappell K, Newman C. Potential tenfold drug overdoses on a neonatal unit. Arch Dis Child Fetal Neonatal Ed 2004;89:F483-4.

24. Larsen GY, Parker HB, Cash J, et al. Standard drug concentrations and smart-pump technology reduce continuous-medication-infusion errors in pediatric patients. Pediatrics 2005;116:e21-5

25. Needham DM, Thompson DA, Holzmueller CG, et al. A system factors analysis of airway events from the Intensive Care Unit Safety Reporting System (ICUSRS). Crit Care Med 2004;32:2227-33.

26. Needham DM, Sinopoli DJ, Thompson DA, et al. A system factors analysis of "line tube, and drain" incidents in the intensive care unit. Crit Care Med 2005;33:1701-7.

27. Durie M, Beckmann U, Gillies DM. Incidents relating to arterial cannulation as identified in 7525 reports submitted to the Australian Incident Monitoring Study (AIMS-ICU). Anaesth Intensive Care 2002;30:60-5.

28. Kunac DL, Reith DM. Identification of priorities for medication safety in neonatal intensive care. Drug Saf 2005;28:251-61.

29. Leonard MS, Cimino M, Shaha S, et al. Risk reduction for adverse drug events through sequential implementation of patient safety initiatives in a children's hospital. Pediatrics 2006;118:e1124-9.

30. Beckmann U, Bohringer C, Carless R, et al. Evaluation of two methods for quality improvement in intensive care: facilitated incident monitoring and retrospective medical chart review. Crit Care Med 2003;31:1006-11.

31. Sharek PJ, Horbar JD, Mason W, et al. Adverse events in the neonatal intensive care unit. Development, testing, and findings of an NICU-focused trigger tool to identify harm in North American NICUs. Pediatrics 2006;118:1332-40. 